\title{
Prevalence Of Narcissism In Adolescents Of Karachi
}

\author{
Aisha Qadir \\ Department of Physiology University of Karachi, \\ Karachi, Pakistan \\ Lubna Naz \\ Department of Physiology University of Karachi, \\ Karachi, Pakistan \\ Samia Mushtaq \\ Department of Physiology University of Karachi, \\ Karachi, Pakistan \\ Nazneen Zehra \\ Department of Physiology University of Karachi, \\ Karachi, Pakistan
}

\begin{abstract}
Narcissism may describe as be in love with own self. The individual may have variety of such behavior that are unfavorable for society such as rudeness, aggressive and violent behavior, selfishness, blaming and discourage others on their own faults, carelessness toward other feelings and emotions, inflated sense of supremacy and self-importance. More likely to involve in crimes and conflicts. Although Narcissistic personality disorder (NPD) is the serious issue but very little amount of work was done on this issue. The aim of this study is to evaluate the prevalence of narcissistic traits in the general youth population. The randomly selected sample of 1145 individuals falls in age group 18 to 25 were selected to estimate the prevalence of NPD .The Narcissistic Personality inventory (NPI-40) based on DSM III criteria was used to find out the prevalence of Narcissism in Study group. The result showed high scores of NPI in youth population 167 male $(47.44 \%)$ and 346 females $(43.63 \%)$ scored $>20$ numbers in NPI. But NPI can only show relative idea of the frequency of narcissism, by scoring high in NPI it could not say certainly that individual lie in category of narcissistic so there is necessitate to more work should be done on this least studied topic to evaluate the true picture of narcissistic behavior in population.
\end{abstract}

Key words: Narcissistic personality disorder, Prevalence of Narcissism, Narcissistic Personality inventory, Self love in adolescents.

\section{INTRODUCTION}

There is much least work on personality disorders was done in our society although it's important to estimate the prevalence of personality disorders because it was concluded from several researches that the personality disorders are responsible for violent behaviors in adolescents. The youngsters who are with a higher scoring of narcissistic, paranoid, and passive-aggressive symptoms are more susceptible to commit variety of violent acts such as arson, assault, breaking and entering, initiating physical fights, robbery, and threats to injure others during their adolescence and early adulthood. Personality disorders are the main reason of failure to keep maintain on personal relations so it leads to increase in frustration that ultimately cause violent and aggressive behavior. (Johnson, J. G.et al; 2000). 
Exact cause of narcissism is still controversial. Some researches show that genetic play considerable role in development of narcissistic behavior while social and cultural environment also responsible for development of NPD. It was observed that when the emotional feelings of a child were neglected and when physical requirement of a child was ignored so all these lead to enhance the likelihood of Personality Disorders. The symptoms of personality disorders are observed higher during adolescents and in early 20s. (Johnson, J. G.et al; 2001).

It was observed that students of present era are on remarkable elevated scores of assertiveness, self-love, narcissistic traits, great expectations, and some extent of stress, anxiety and pitiable mental health, and lower on self-confidence. (Carter, R. R.et al; 2012). Individuals with narcissistic personality disorder usually think that the world is in their control. This perception is characterized by a lack of ability to understand with feelings with others and a desire to keep the attention on themselves most of the time

Narcissism is one of the major personality disorders present among adolescents. The narcissism is the Greek word which is related by a traditional Greek story of a handsome boy who carelessly ignored the affection of others when he fell in love with his own reflection when he saw his image in the water of the fountain .Now in modern era the word narcissism means that the narcissism is the quality of that individual who has only interest with his own self and feelings and they only concern about their self respect.

Narcissistic personality disorder is a psychological disorder in which suffered have and bombastic sense of their own significance, a profound desire for appreciation and a lack of empathy for others. But in reality behind this mask of ultra confidence present a friable selfesteem that's vulnerable to the even negligible criticism. (Levy, K. N.et al; 2009).

Some of The more frequently occurring characteristics which can be observed in individuals with narcissism are a high sense of their greatness, a high perception of extraordinary personality, extreme level of talent, violent and aggressive behavior, live in world of fantasies, they may be egoistic and do self admiration, Strong desire of be center of attention, urge to be admired, arrogant and rude behavior, willing to be successful and accomplish desire goals and targets. (Ronningstam, E., \& Gunderson, J. ;1990).In general population it was seen that in young age majority of boys and girls are too much concerned about their physical appearance .Young men want to increase their muscle mass and physique while girls tend to reduce their body size .for the sake of this desire they use to practice unhealthy behaviors such as intense exercise, brutal restricted dietary patterns ,use of steroids and other medications to achieve their required targets this behaviors are one of the symptoms of Narcissistic behavior .( Davis, C., \& Scott-Robertson, L. ;2000).however the large number of criteria that are followed for diagnosis of narcissism is DSM-IV criteria. These criteria emphasize of sense of grandiosity .By placing most of the diagnostic emphasis on overt grandiosity. (Cain, N. M.; 2008).

Narcissism may further divided into two sub types, The Overt or thick skinned type and the covert or thin-skinned type .both types may share many characteristics of Narcissistic personality disorders but in Overt type the individual have exaggerated sense of self importance, extreme desire to get priority and superiority, tend to achieve power and authority, have inflated aggressive behavior with extreme rage. Dislike of overt narcissistic people the individuals with covert type of narcissism may hide their aggression and that leads to depression and high level of stress in them, they feel guilt and shame on themselves, they want to blend with others. The mostly live in fantasies. 
Narcissism cause severe complications in maintaining relationships cause to create problems at working place and school. It also leads to depression and stress. The individual with high scores of narcissism are on high risk of alcohol consumption and drug abuse. These individuals are also preoccupied with negative thoughts and behaviors like suicide and injure themselves. (Lubit, R.; 2002).

\section{METHODOLOGY}

In order to estimate the prevalence of narcissistic behavior in youngsters we randomly select 1145 people which lie in age groups between 18 to 25. There was no discrimination of gender and qualification .

The study was survey based, the questionnaire was designed according to Narcissistic personality inventory(NPI).The NPI was designed by Raskin and Hall in1979 for the measurement of narcissism as a personality trait in social psychological research.NPI follow the DSM-III criteria to diagnose the narcissistic traits in study subjects. The NPI consist of a list which have pairs of 40 questions. Form each pair the study subjects have to select that option which he might be feel most accurately reflects his personality. The Narcissistic Personality Inventory is distributed on 7 areas that show different diagnostic features on NPD: Authority, Exhibitionism, Superiority, Exploitativeness, Vanity, Self-Sufficiency, and Entitlement. In the list of 40 questions different questions are related to different features such as the chart present below shows that which question numbers are related to which feature.

Authority: $1,8,10,11,12,32,33,36$

Exhibitionism: 2, 3, 7, 20, 28, 30, 38

Superiority: 4, 9, 26, 37, 40

Exploitativeness: 6, 13, 16, 23, 35

Vanity: 15, 19, 29

Self-sufficiency: 17, 21, 22, 31, 34, 39

Entitlement: 5, 14, 18, 24, 25, 27. (Raskin, R.; Terry, H.; 1988)

All these 7 Diagnostic features were observed separately by calculating mean of scores that study subjects attains in each question related to specific feature.(TABLE

The aim and objectives of study was explained in front of each and every study subject and after taking their contest the questionnaire was filled by individual through interview. The each questionnaire was checked online to find out scores of each and every study subject.

4 categories of scores were designed which were 0-11 means mild narcissism, 12-15 average narcissism, 16-20 moderate narcissism and $>20$ overt narcissism.

The study subjects were placed in respective category according to their scores in NPI. 


\section{RESULTS AND DISCUSSION}

Among The sample size of 1145 the 352 were male subjects while 793 were female .therefore $30.74 \%$ were male and $69.26 \%$ were females included in this study. (Figure 1)

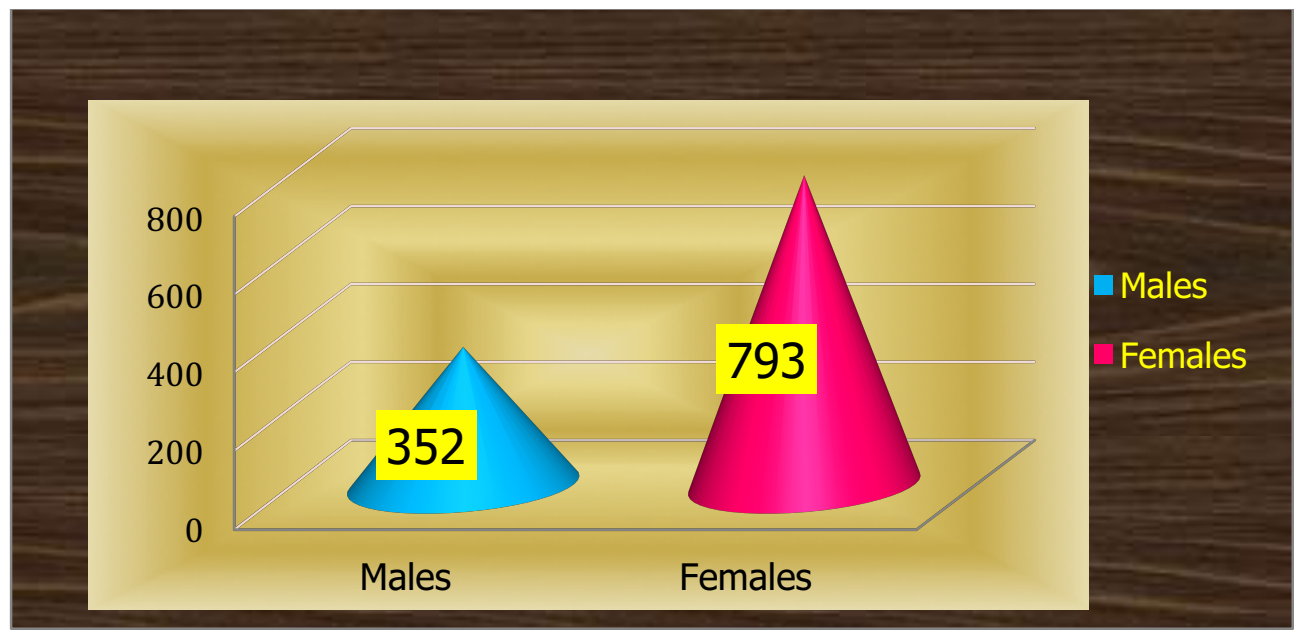

FIGURE 1: GENDER OF STUDY SUBJECT

Majority of study subjects approximately $87.34 \%$ were belonged to middle socioeconomic class.3.41\% were belonged to low socioeconomic class while $9.26 \%$ had high socioeconomic status. (Figure 2)

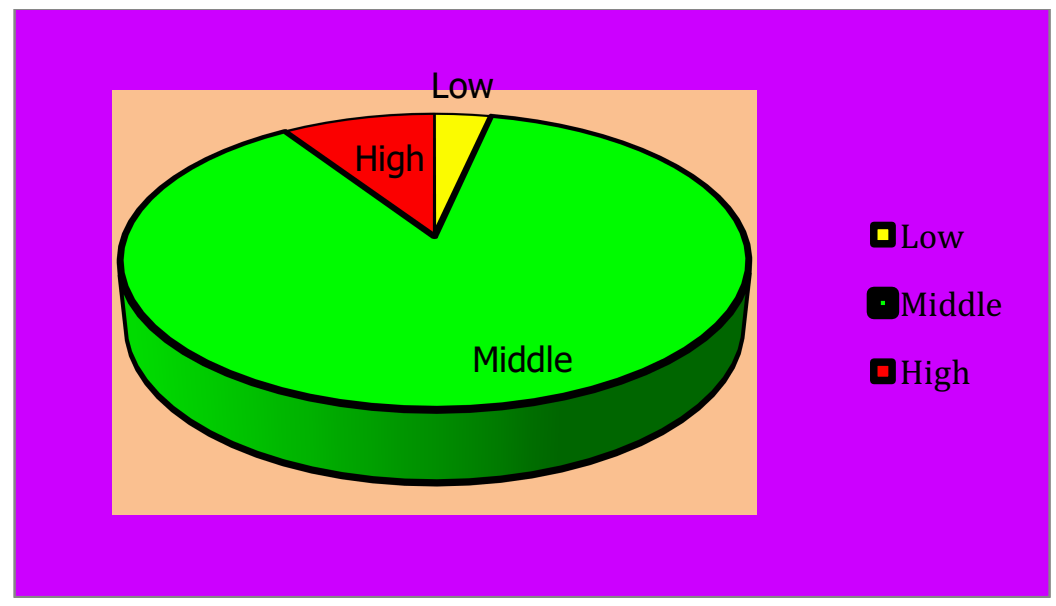

FIGURE 2: SOCIOECONMOIC STATUS OF STUDY SUBJECTS.

It was observed by calculating scores of study subjects according to NPI that $9.08 \%$ subjects have mild narcissism.23.14\% subjects had scored average in NPI ,The scores of $32.31 \%$ were in between 16 to 20 While $35.90 \%$ have overt narcissism.(FIGURE 3)

By Findings of NPI it was observed that:

In males $(\mathrm{n}=352)$

- $10(2.84 \%)$ were in between category of $0-11$

- $82(23.30 \%)$ were in between 12-15

- $96(27.27 \%)$ were in between 16-20

- $167(47.44 \%)$ were in between category of $>20$ (FIGURE 4 )

While In females $(\mathrm{n}=793)$

- 61(7.69\%) were in between category of 0-11

- $147(18.54 \%)$ were in between $12-15$ 
- $244(30.77 \%)$ were in between $16-20$

- $348(43.63 \%)$ were in between category of $>20$ (FIGURE 5)

There was not a significant difference was observed between prevalence of narcissism in between male and female genders both scores high in NPI.

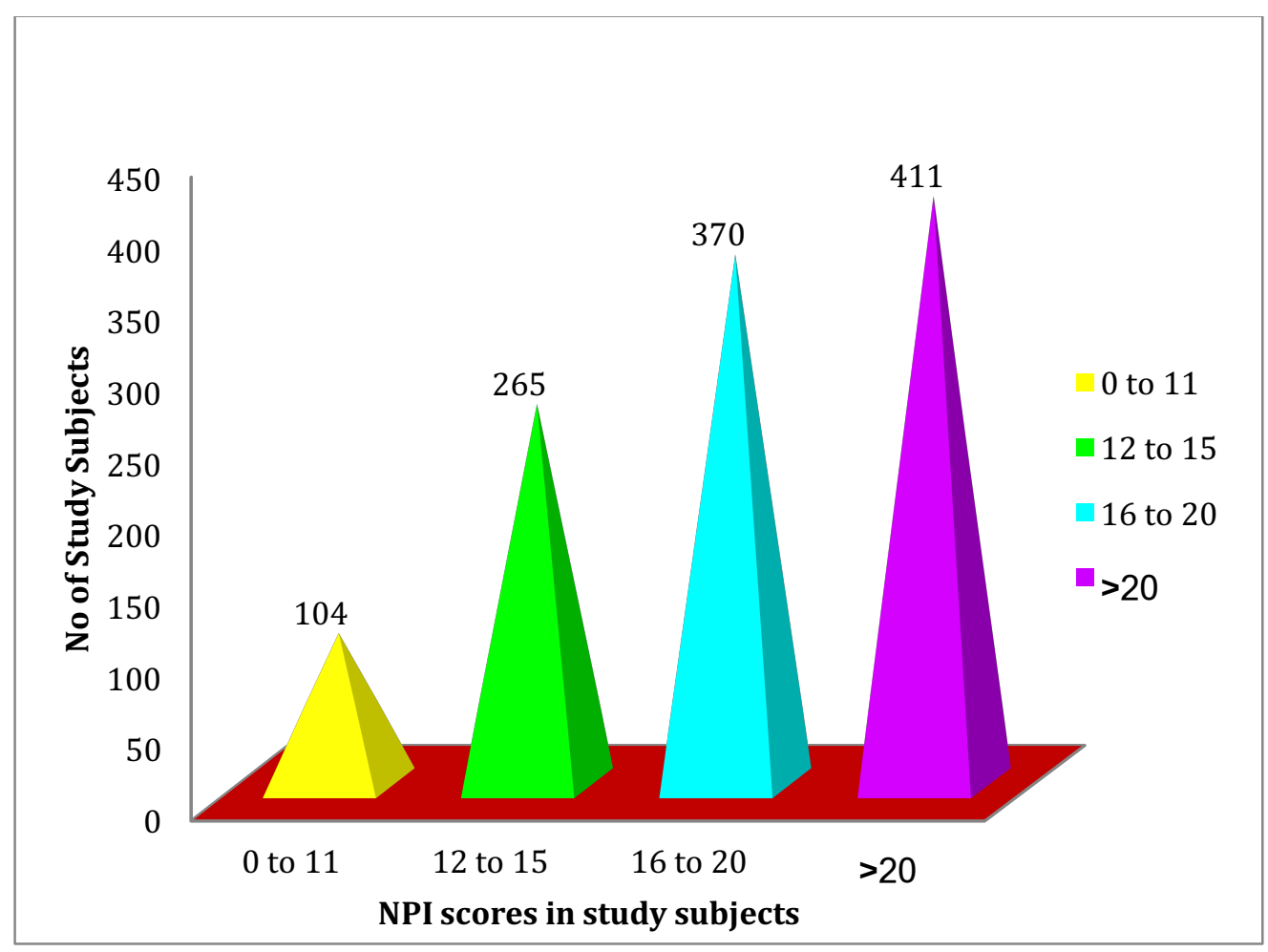

FIGURE 3: NPI SCORING OF STUDY SUBJECTS

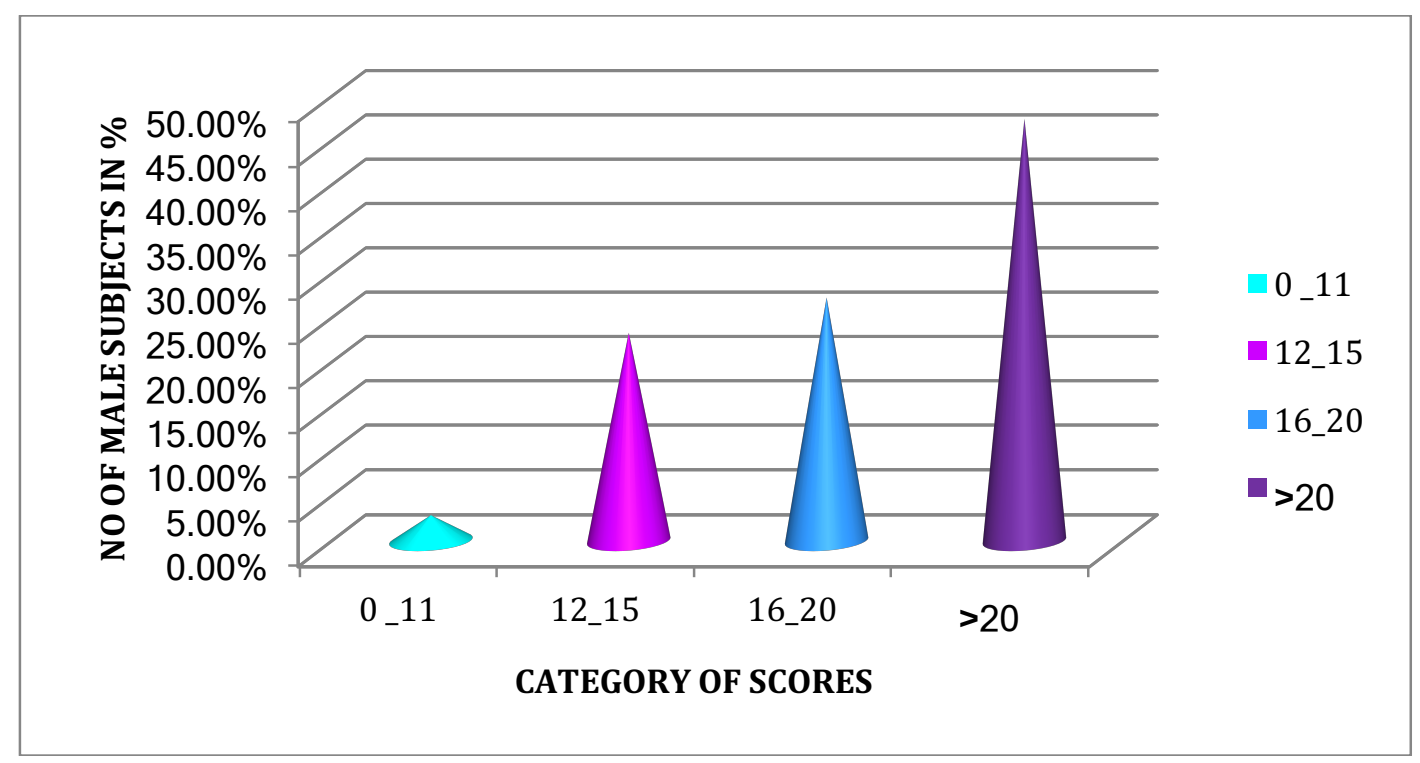

FIGURE 4: MALES SCORING OF NPI 


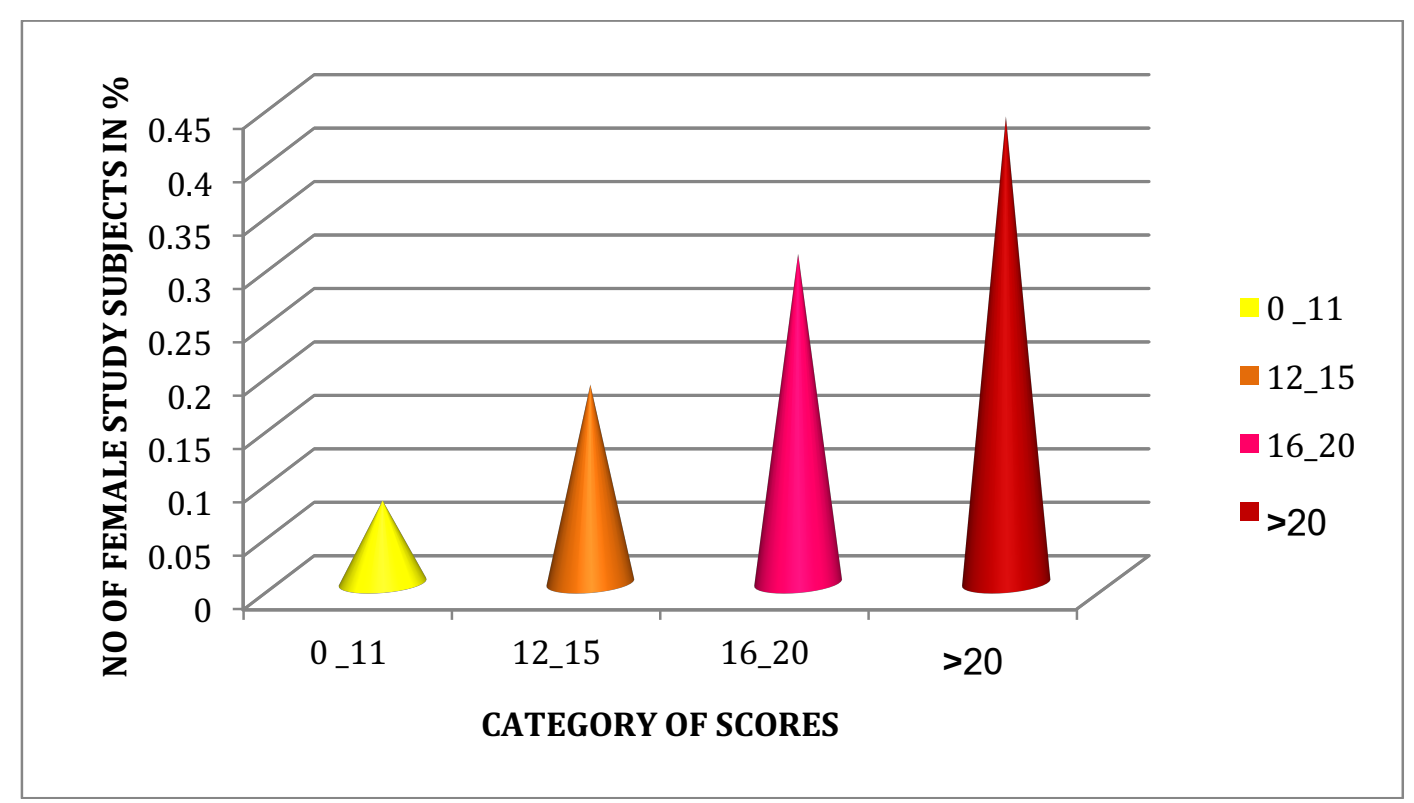

FIGURE 5: FEMALES SCORING OF NPI

Table 1 shows 7 diagnostic features of NPD according to NPI. Column I shows the questions number related to the particular symptom mention above which are Authority, Exhibitionism, Superiority, Exploitativeness, Vanity, Self-Sufficiency, and Entitlement. Column II shows the frequency of study subject having these characteristics .Column III shows the frequency of study subjects in \% .Column IV shows the mean of frequency of study subjects enlisted in each group of symptoms. (Table 1) 


\begin{tabular}{|c|c|c|c|}
\hline $\begin{array}{c}\text { DIAGNOSTIC } \\
\text { FEATURES }\end{array}$ & NO OF S.S & NO OF S.S IN \% & MEAN \\
\hline \multicolumn{4}{|c|}{ AUTHORITY } \\
\hline 1 & 721 & $62.97 \%$ & 568.125 \\
\hline 8 & 861 & $75.20 \%$ & \\
\hline 10 & 648 & $56.59 \%$ & \\
\hline 11 & 546 & $47.69 \%$ & \\
\hline 12 & 492 & $42.97 \%$ & \\
\hline 32 & 498 & $43.49 \%$ & \\
\hline 33 & 491 & $42.88 \%$ & \\
\hline 36 & 288 & $25.15 \%$ & \\
\hline \multicolumn{4}{|c|}{ EXHIBITONISM } \\
\hline 2 & 371 & $32.40 \%$ & 426.1428571 \\
\hline 3 & 415 & $36.24 \%$ & \\
\hline 7 & 445 & $38.86 \%$ & \\
\hline 20 & 385 & $33.62 \%$ & \\
\hline 28 & 592 & $51.70 \%$ & \\
\hline 30 & 505 & $44.10 \%$ & \\
\hline 38 & 270 & $23.58 \%$ & \\
\hline \multicolumn{4}{|c|}{ SUPERORITY } \\
\hline 4 & 620 & $54.15 \%$ & 533 \\
\hline 9 & 509 & $44.45 \%$ & \\
\hline 26 & 733 & $64.02 \%$ & \\
\hline 37 & 469 & $40.96 \%$ & \\
\hline 40 & 334 & $29.17 \%$ & \\
\hline \multicolumn{4}{|c|}{ EXPLOITATION } \\
\hline 6 & 449 & $39.21 \%$ & 476.6 \\
\hline 13 & 519 & $45.33 \%$ & \\
\hline 16 & 459 & $40.09 \%$ & \\
\hline 23 & 410 & $35.81 \%$ & \\
\hline 35 & 546 & $47.69 \%$ & \\
\hline \multicolumn{4}{|c|}{ VANITY } \\
\hline 15 & 171 & $14.93 \%$ & 395.3333333 \\
\hline 19 & 630 & $55.02 \%$ & \\
\hline 20 & 385 & $33.62 \%$ & \\
\hline \multicolumn{4}{|c|}{ SELF SUFFICIENCY } \\
\hline 17 & & $54.76 \%$ & 506.8333333 \\
\hline 21 & & $45.59 \%$ & \\
\hline 22 & & $47.25 \%$ & \\
\hline 31 & & $54.32 \%$ & \\
\hline 34 & & $37.99 \%$ & \\
\hline 39 & & $25.68 \%$ & \\
\hline \multicolumn{4}{|c|}{ ENTILEMENT } \\
\hline 5 & & $63.93 \%$ & 497.6667 \\
\hline 14 & & $19.04 \%$ & \\
\hline 18 & & $38.43 \%$ & \\
\hline 24 & & $30.92 \%$ & \\
\hline 25 & & $48.56 \%$ & \\
\hline 27 & & $59.91 \%$ & \\
\hline
\end{tabular}

Where, S.S= Study subjects 
It was observed that the sense of authority and superiority were observed very high in study subjects. (Figure 6)

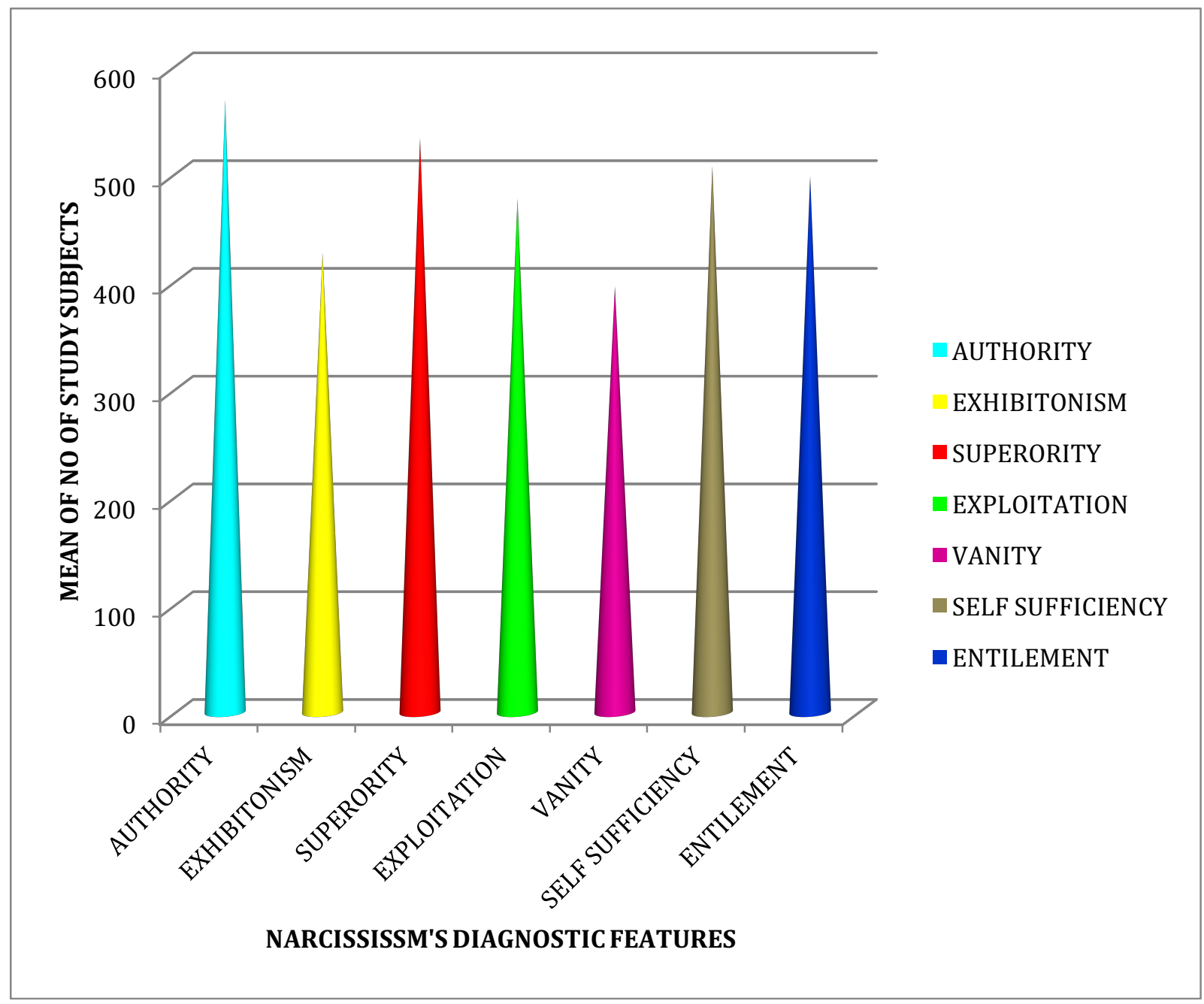

FIGURE 6: PREVALENCE OF DIAGNOSTIC FEATURES OF NARCISSISSM IN STUDY SUBJECTS

It was found from subsequent study that the adolescent of population mean age of 21.5years of age attained high scores in NPI. But High scores are not concrete diagnosis of Narcissistic personality disorder.bt it is helpful for rough estimation of prevalence of Narcissistic personality disorder (NPD). According to Davis, C., \& Scott-Robertson, L. (2000) Youngsters are more preoccupied, possessive, perfectionist, anhedonic, and pathologically narcissistic than the other age groups of the population. It was also found in present study that both male and females study subjects were the victims of NPD.But males gained slightly higher NPI scores than females. The mean score of Males were 19.45and female were 18.82. (TABLE 2)

TABLE 2: NARCISSISTIC PERSONALITY DISORDER (NPI) SCORES

\begin{tabular}{|c|c|c|}
\hline CALCULATION & MALES & FEMALES \\
\hline $\mathrm{A}$ & 6848 & 15717 \\
\hline $\mathrm{B}$ & 352 & 793 \\
\hline MEAN (A/B) & 19.454 & 18.82 \\
\hline
\end{tabular}

$A=$ Sum of scores gained

$B=$ total no of all study subjects in respective group (Males/Females)

Mean=A/B 
In our studies it was found that the mean scoring of NPI was observed 17.595 which is higher than average of scores of US Universities undergraduates (15.6)according to Raskin and Terry,1988 and also higher than US Adults(15.3) according to Pinsky and Young,2009.

\section{CONCLUSION}

It can be concluded by our study that Narcissism would be present in youngsters that could be problematic for their own selves and also for the society they live in. They may be the cause of distress for all .So, there is the extreme need to do further study on Narcissistic personality disorder, along with the help of psychiatric and other expertise .which can provide us the vivid picture of prevalence of NPD in population, which would be promising for better diagnosis and other treatment measures of NPD .

\section{References}

Back, M. D., Schmukle, S. C., \& Egloff, B. (2010). Why are narcissists so charming at first sight? Decoding the narcissism-popularity link at zero acquaintance. Journal of personality and social psychology, 98(1), 132.

Cain, N. M., Pincus, A. L., \& Ansell, E. B. (2008). Narcissism at the crossroads: Phenotypic description of pathological narcissism across clinical theory, social/personality psychology, and psychiatric diagnosis. Clinical psychology review, 28(4), 638-656.

Carter, R. R., Johnson, S. M., Exline, J. J., Post, S. G., \& Pagano, M. E. (2012). Addiction and “Generation Me”: narcissistic and prosocial behaviors of adolescents with substance dependency disorder in comparison to normative adolescents. Alcoholism treatment quarterly, 30(2), 163-178.

Chabrol, H., Chouicha, K., Montovany, A., Callahan, S., Duconge, E., \& Sztulman, H. (2001). [Personality disorders in a nonclinical sample of adolescents]. L'Encephale, 28(6 Pt 1), 520-524.

Collins, J. K., \& LaGanza, S. (1982). Self-recognition of the face: A study of adolescent narcissism. Journal of youth and adolescence, 11(4), 317-328.

Davis, C., \& Scott-Robertson, L. (2000). A psychological comparison of females with anorexia nervosa and competitive male bodybuilders: body shape ideals in the extreme. Eating behaviors, 1(1), 33-46.

Johnson, J. G., Cohen, P., Smailes, E., Kasen, S., Oldham, J. M., Skodol, A. E., \& Brook, J. S. (2000). Adolescent personality disorders associated with violence and criminal behavior during adolescence and early adulthood. American Journal of psychiatry.

Johnson, J. G., Cohen, P., Smailes, E. M., Skodol, A. E., Brown, J., \& Oldham, J. M. (2001). Childhood verbal abuse and risk for personality disorders during adolescence and early adulthood. Comprehensive psychiatry, 42(1), 16-23.

Lester, D. (1998). Adolescent suicide risk today: A paradox. Journal of Adolescence, 21(4), 499-503.

Levy, K. N., Chauhan, P., Clarkin, J. F., Wasserman, R. H., \& Reynoso, J. S. (2009). Narcissistic pathology: Empirical approaches. Psychiatric Annals, 39(4).

Lubit, R. (2002). The long-term organizational impact of destructively narcissistic managers. The Academy of Management Executive, 16(1), 127-138.

Raskin, R.; Terry, H. (1988). "A principal-components analysis of the Narcissistic Personality Inventory and further evidence of its construct validity". Journal of Personality and Social Psychology, Vol 54(5), 890-902.

Ronningstam, E., \& Gunderson, J. (1990). Identifying criteria for narcissistic personality disorder. American Journal of Psychiatry, 147(7), 918-922.

Russ, E., Shedler, J., Bradley, R., \& Westen, D. (2008). Refining the construct of narcissistic personality disorder: Diagnostic criteria and subtypes. American Journal of Psychiatry.

SALMAN AKHTAR, M. D., \& Thomson Jr, J. A. (1982). Overview: Narcissistic personality disorder. Am J Psychiatry, 139(1).

Schwab, M., \& Siever, J. (1993). Prevalence and stability of the DSM-III-R personality disorders in a communitybased survey of adolescents. Am J Psychiatry, 1(50), 1237.

Stolorow, R. D. (1975). Toward a functional definition of narcissism. The International journal of psycho-analysis, 56, 179. 
Qadir, A., Naz, L., Mushtaq, S., \& Zehra, N. (2019). Prevalence Of Narcissism In Adolescents Of Karachi. Advances in Social Sciences Research Journal, 6(3) 19-28.

Twenge, J. M. (2009). Generational changes and their impact in the classroom: teaching Generation Me. Medical education, 43(5), 398-405.

Vaglum, P. (1999). The narcissistic personality disorder and addiction. In Treatment of personality disorders (pp. 241-253). Springer US. 